\title{
Avaliação da imagem corporal em relação ao nível de atividade física habitual e o comportamento sedentário de adolescentes
}

Valter Paulo Neves Miranda, Núbia de Souza de Morais, Karina Rafaela Ramos, Sylvia do Carmo Castro Franceschini, Silvia Eloiza Priore

\begin{abstract}
Resumo
A imagem corporal pode ser definida como a forma em que o indivíduo se percebe ou se sente em relação ao tamanho, a forma e o contorno do próprio corpo. Atualmente, o corpo magro, com baixos níveis de gordura, tem sido valorizado pela mídia, meio social, família e amigos. As adolescentes do sexo feminino e com excesso de peso podem ser considerados grupo de risco ao desenvolvimento de distúrbios da imagem corporal, por internalizarem e desejarem veementemente um tipo corporal mais delgado. O aumento do nível habitual de atividade física (NAF) e diminuição do comportamento sedentário (CS) podem elevar o gasto de energia, com isso diminuir o excesso de peso e aumentar a consciência corporal. No entanto, há escassez de informações sobre a relação do NAF com a imagem corporal. Avaliar a associação da imagem corporal com nível de atividade física habitual (NAF), composição corporal e o comportamento sedentário (CS) de adolescentes do sexo feminino. Estudo transversal e exploratório com 125 adolescentes do sexo feminino, de 14 a 19 anos, de Viçosa, MG. A imagem corporal foi avaliada pela Escala de Silhuetas e pelo Body Shape Questionnaire (BSQ). O peso e a estatura foram aferidos para o cálculo do índice de massa corporal, sendo este categorizado conforme os pontos de corte da Organização Mundial da Saúde específicos para adolescentes. O perímetro da cintura (PC) foi aferido para a avaliação da relação cintura/estatura (RCE). O percentual de gordura corporal (\%GC) foi obtido pela balança Tanita BC543 (TMAB®, Londres, Reino Unido), sendo classificado de acordo com os pontos de corte propostos por Williams et al.(1992). O NAF foi avaliado pelo Recordatório de Atividade Física de 24h (R24h), e o comportamento sedentário por meio do tempo de tela (TT) de TV, vídeo game, computador e tablets, e separadamente, o tempo de tela e tempo do celular (TC). O CS foi considerado elevado sendo o TT ou o TC maior ou igual a $2 \mathrm{~h}$. Tanto a avaliação do NAF e do CS foram avaliadas em um dia da semana que representasse a rotina da adolescente. A média de idade foi de 16,5 $\pm 1,5$ anos, sendo a maioria eutrófica $(77,59 \%)$, sedentária/baixo NAF $(84,17 \%)$, com TT $(85,24 \%)$ e TC $(58,68 \%)$ elevados. A insatisfação corporal manifestou-se em $40,59 \%$ pelo BSQ e em $45,83 \%$ pela Escala se Silhuetas. A distorção corporal manifestou-se em 52,89\% das participantes. As medidas de composição corporal, juntamente com o tempo de celular e o NAF mostraram associação com a insatisfação corporal; sendo as adolescentes mais ativas as mais insatisfeitas. A associação foi observada entre a insatisfação corporal com todas as medidas de composição corporal, comportamento sedentário e NAF das adolescentes. Com este estudo foi possível enfatizar a importância de se avaliar diferentes aspectos da imagem corporal em relação a variáveis que representam o estilo de vida dos adolescentes.
\end{abstract}

Descritores: Imagem Corporal; Adolescentes; Estilo de Vida. 